\title{
Applicability of colon capsule endoscopy as pan-endoscopy: From bowel preparation, transit, and rating times to completion rate and patient acceptance
}

\section{(ㄷ)(1) $(2) \Theta$}

\section{Authors}

Fanny E.R. Vuik, Sarah Moen, Stella A.V. Nieuwenburg, Eline H. Schreuders, Ernst J. Kuipers, Manon C.W. Spaander

\section{Institution}

Department of Gastroenterology and Hepatology, Erasmus MC University Medical Center, Rotterdam, the Netherlands

submitted 13.4 .2021

accepted after revision $\quad 2.7 .2021$

\section{Bibliography \\ Endosc Int Open 2021; 09: E1852-E1859 \\ DOI 10.1055/a-1578-1800 \\ ISSN 2364-3722 \\ (C) 2021. The Author(s).}

This is an open access article published by Thieme under the terms of the Creative Commons Attribution-NonDerivative-NonCommercial License, permitting copying and reproduction so long as the original work is given appropriate credit. Contents may not be used for commercial purposes, or adapted, remixed, transformed or built upon. (https://creativecommons.org/licenses/by-nc-nd/4.0/)

Georg Thieme Verlag KG, Rüdigerstraße 14,

70469 Stuttgart, Germany

\section{Corresponding author}

Prof. Dr. Manon C.W. Spaander, MD, PhD, Department of Gastroenterology and Hepatology, Erasmus MC University Medical Center, Gravendijkwal 230, 3015 CE Rotterdam, The Netherlands

Fax: +31 (0) 107035172

v.spaander@erasmusmc.nl

Supplementary material is available under https://doi.org/10.1055/a-1578-1800

\section{ABSTRACT}

Background and study aims Colon capsule endoscopy (CCE) has the potential to explore the entire gastrointestinal tract. The aim of this study was to assess the applicability of CCE as pan-endoscopy.

Patients and methods Healthy participants received CCE with bowel preparation (bisacodyl, polyethylene electrolyte glycol (PEG) + ascorbic acid) and booster regimen (metoclopramide, oral sulfate solution (OSS)). For each segment of the gastrointestinal tract, the following quality parameters were assessed: cleanliness, transit times, reading times, patient acceptance and safety of the procedure. When all gastrointestinal segments had cleansing score good or excellent, cleanliness of the whole gastrointestinal tract was assessed as good. Participants' expected and perceived burden was assessed by questionnaires and participants were asked to grade the procedure (scale $0-10$ ). All serious adverse events (SAEs) were documented.

Results A total of 451 CCE procedures were analyzed. A good cleansing score was achieved in the stomach in $69.6 \%$, in the SB in $99.1 \%$ and in the colon in $76.6 \%$. Cleanliness of the whole gastrointestinal tract was good in $52.8 \%$ of the participants. CCE median transit time of the whole gastrointestinal tract was 583 minutes IQR 303-659). The capsule reached the descending colon in $94.7 \%$. Median reading time per procedure was 70 minutes (IQR 57-83). Participants graded the procedure with a 7.8. There were no procedure-related SAEs.

Conclusions CCE as pan-endoscopy has shown to be a safe procedure with good patient acceptance. When cleanliness of all gastrointestinal segments per patient, completion rate and reading time will be improved, CCE can be applied as a good non-invasive alternative to evaluate the gastrointestinal tract.

\section{Introduction}

Colon capsule endoscopy (CCE) is a noninvasive technique to explore the colon mucosa using an ingestible, wireless, and disposable capsule [1]. Many studies have shown that CCE has good diagnostic value for abnormalities such as polyps and colorectal carcinomas [2,3]. Therefore, CCE can be used when colonoscopy is not possible or incomplete $[4,5]$. However, CCE provides images of the entire gastrointestinal tract, and therefore, has the potential to be used as a diagnostic tool for all gastrointestinal mucosal pathology [6]. 
Despite its noninvasive character and its potential to explore the entire gastrointestinal tract, implementation of CCE as panendoscopy has not yet been achieved. The diagnostic accuracy of CCE as pan-endoscopy is highly dependent on several quality parameters, such as bowel preparation scores, transit times, and capsule completion rate. Optimal stomach and bowel preparation is needed for high-quality CCE images. However, current preparation protocols have led to contradictory results and there is no consensus on which bowel preparation schedule has the best results $[7,8]$. Moreover, to obtain images from the entire gastrointestinal tract, the capsule needs to be excreted within the battery life [9]. On the other hand, transit times should not be too fast, because lesions of the gastrointestinal tract may then be missed.

The applicability of CCE is also highly dependent on other factors, such as the workability for the staff, patient acceptance, and safety of the procedure. Evaluation of the images can be time-consuming and training is necessary to adequately review the images of the gastrointestinal tract [10].

CCE provides a noninvasive alternative and is associated with significantly less discomfort compared to conventional endoscopy [11]. However, the large volume of bowel preparation can be a challenge for patients and when CCE is positive, patients still need to undergo an endoscopy [9]. Finally, the implementation of a certain diagnostic tool can only expand when the procedure is safe. CCE has shown to be a safe procedure with few described serious events so far, although patients with obstructive symptoms should be treated with care [1].

In this study, different quality parameters for CCE for each gastrointestinal segment and participant preferences about the CCE procedure were evaluated to investigate the applicability of CCE as pan-endoscopy.

\section{Patients and methods}

\section{Participants}

Asymptomatic participants aged 50 to 75 years who underwent CCE were included [12]. People participating in the Rotterdam Study were eligible to participate in this study if they were aged 50 to 75 years and able to give informed consent. Participants were excluded when they met one of the following conditions: 1) unable or unwilling to sign written informed consent; 2) severe or terminal disease with a life expectancy less than 5 years; 3) allergy or known contraindication to the medications used in this study; 4) chronic heart failure New York Heart Association III or IV; 5) severe kidney insufficiency (Glomerular filtration rate $<30 \mathrm{~mL} / \mathrm{min} / 1.73 \mathrm{~m}^{3}$ ); 6) dysphagia or swallowing disorder; 7) increased risk for capsule retention (M. Crohn; prior abdominal surgery likely to cause bowel obstruction); 8) pacemaker or other implantable cardiac defibrillator; 9) magnetic resonance imaging scheduled within 14 days after ingestion of the capsule; 10) risk of congenital extended QT syndrome and/ or medication known to extend the QT interval; or 11) diabetes mellitus with use of insulin.

The study was approved by the Medical Ethics Committee of the Erasmus MC (registration number MEC-2015-453, date of approval: 26-04-2016). The protocol was registered in the
Netherlands National Trial Register (NTR; NTR6321, registration date: 23-11-2016). All participants signed written informed consent before participation in the study.

\section{Colon capsule endoscopy}

The second-generation colon capsule (PillCam COLON 2, Medtronic) was used. The ingestion of the capsule usually took place at 9 a.m. in the presence of a physician. A sensor belt was attached to the participant before ingesting the colon capsule. The sensor belt receives transmission data from the colon capsule. After ingesting the capsule, participants went home. The belt was taken off by participants at $8 \mathrm{p}$.m. or earlier when the capsule had already left the body.

The participants received bowel preparation consisting of $5 \mathrm{mg}$ bisacodyl, $2 \mathrm{~L}$ polyethylene electrolyte glycol (PEG + asc) (Moviprep; Norgine, Amsterdam, the Netherlands) and $2 \mathrm{~L}$ water, both split dose. They received a booster regimen with $10 \mathrm{mg}$ metoclopramide and $0.5 \mathrm{~L}$ oral sulfate solution (OSS) (Eziclen, Zambon, the Netherlands) - in split dose $0.25 \mathrm{~L}$ directly after small bowel recognition and $0.25 \mathrm{~L} 3$ hours after small bowel recognition (for detailed bowel preparation scheme see Supplementary Table 1).

Before starting this trial, a pilot study was performed to compare two types of booster: PEG + asc or OSS. Cleansing scores were similar, but due to a higher completion rate for OSS, this booster was chosen for the conduct of this study (see supplementary section).

\section{Quality parameters}

For each part of the gastrointestinal tract, the following quality parameters were assessed: cleanliness, transit times, reading times, patient acceptance, and safety of the procedure.

\section{Cleanliness}

Cleansing of the stomach, small bowel, and colon was graded according to three different grading scales ( $>$ Table 1 ). Stomach cleansing was measured by the proportion of visualized mucosa (<70\% poor, 70\%-90\% fair, >90\% good) [13]. Small bowel cleansing was measured by the proportion of visualized mucosa (<25\% poor, $25 \%-50 \%$ fair, $50 \%-75 \%$ good, $>75 \%$ excellent) and degree of bubbles, debris and bile ( $>50 \%$ poor, 25\%-50\% moderate, 5\%-25\% good, < $5 \%$ excellent) [14]. Colon cleansing was measured by cleansing level (poor, fair, good, excellent) and the bubbles effect scale (interference of bubbles in examination defined as insignificant or significant) [15]. The quality of colon cleanliness was evaluated for each segment of the colon: cecum, ascending colon, transverse colon, descending colon, and rectum and an overall colon cleansing grade was assessed using the same grading system. An overall score for cleanliness of the entire gastrointestinal tract was defined "good" when both stomach cleansing was good and small bowel cleansing as well as colon cleansing were either good or excellent. 
- Table 1 Definition of cleansing grading scales for the stomach, small bowel, and colon.

\begin{tabular}{l|l}
\hline \multicolumn{2}{l}{ Gastric grading scale } \\
\hline Poor & $<70 \%$ of the mucosa was observed \\
\hline Fair & $70 \%-90 \%$ of the mucosa was observed \\
\hline Good & $>90 \%$ of the mucosa was observed \\
\hline
\end{tabular}

Small bowel grading scale

Proportion of visualized mucosa

\begin{tabular}{|l|l|}
\hline Poor & $<25 \%$ \\
\hline Fair & $25 \%-50 \%$ \\
\hline Good & $50 \%-75 \%$ \\
\hline Excellent & $>75 \%$ \\
\hline
\end{tabular}

Degree of bubbles, debris, and bile

\begin{tabular}{|l|l|}
\hline Poor & $>50 \%$, severe obscuration \\
\hline Fair & $25 \%-50 \%$, moderate obscuration \\
\hline Good & $5 \%-25 \%$, mild obscuration \\
\hline Excellent & $<5 \%$, no obscuration \\
\hline
\end{tabular}

Colon grading scale

Cleansing level grading scale

\begin{tabular}{l|l} 
Poor & Large amount of fecal residue precluding a
\end{tabular} complete examination

\begin{tabular}{|l|l|}
\hline Fair & $\begin{array}{l}\text { Enough feces or dark fluid present to prevent } \\
\text { a reliable exam }\end{array}$ \\
\hline Good & $\begin{array}{l}\text { Small amount of feces or dark fluid not inter- } \\
\text { fering with examination }\end{array}$ \\
\hline Excellent & No more than small bits of adherent feces \\
\hline
\end{tabular}

Bubbles interfering effect scale

Insignificant No bubbles/content/blurry images or so that they do not interfere with the examination. Less than $10 \%$ of surface area is obscured

\begin{tabular}{l|l} 
Significant & Bubbles/content/blurry images that interfere
\end{tabular} with the examination

More than $10 \%$ of surface area is obscured

\section{Transit times}

For each CCE procedure the overall completion rate was evaluated and the transit times were calculated for the stomach, small bowel and colon separately by Rapid Software v7.0 (Medtronic, Minneapolis, Minnesota, United States). Esophageal transit time is usually so fast that only a few images of the esophagus can be obtained. Therefore, for the esophagus, Zline objectification was evaluated, which is a commonly used marker for distal esophageal mucosa visualization in capsule endoscopy [16].

\section{Reading times by the staff}

CCE reading and evaluation was performed by one gastroenterologist, three medical doctors, and one endoscopy nurse. The esophagus was observed by scrolling manually through the images. To observe the mucosa of the stomach and small bowel, both sides of the colon capsule were used at the same time. The images were viewed at a rate that was comfortable for the reviewer, with an average speed of around 10 images per second. The detailed procedure of CCE reading for the colon has been described elsewhere [7]. In short, reading the images of the colon was divided into three phases. A preview phase, in which both sides of the capsule were viewed simultaneously with a high speed to capture landmarks. A review phase which consisted of careful assessment and capture of all the relevant findings. And a report phase in which the findings were evaluated and described. For each part of the gastrointestinal tract, the median reading time by the staff was evaluated. The reading time per procedure was also determined.

\section{Patient acceptance}

Participants were asked to fill in two questionnaires, one regarding their expectations (filled in prior to the CCE procedure) and one regarding their evaluation of CCE (filled in after the procedure). Participants were asked to grade the procedure on a scale from 0 to 10 . They were also asked to grade their expected and perceived burden on a 5-point Likert scale (not at all, just a bit, a little, fairly, strongly). Questions on different aspects of burden (overall burden, pain, and shame) of both the bowel preparation and CCE procedure itself were included in the questionnaires. Specific causes of burden were further evaluated, namely swallowing the capsule, more stomach ache than usual, hindrance in daily activities, and trouble sleeping. Burden of swallowing the capsule and more stomach ache than usual were graded as either present or not present. Hindrance in daily activities was graded as present or not present, and was evaluated for both the day prior to the procedure, the whole procedure day, and the day after the procedure. Finally, trouble sleeping was graded as present or not present, and was evaluated for both the night before the procedure and the night after the procedure.

\section{Safety of the procedure}

Safety of the procedure was measured by the number of (serious) adverse events (AEs).

\section{Statistical analysis}

Quality scores were presented as mean with standard deviation (SD) or medians with interquartile range (IQR). For differences between proportions of categorical variables the $\mathrm{X}^{2}$-test was used. For all tests a significance level of 0.05 was used. Analyses were performed in IBM SPSS v.24.

\section{Results}

A total of 451 CCE procedures were included, $46.1 \%$ were performed in men with a mean age (SD) of 66.8 (4.8) years. 
- Table 2 Cleansing scores for the stomach, small bowel, and colon.

Stomach cleansing - proportion of visualized mucosa $(N=437)$

\begin{tabular}{|l|l|}
\hline Poor & $20(4.6)$ \\
\hline Fair & $113(25.9)$ \\
\hline Good & $304(69.6)$ \\
\hline
\end{tabular}

SB cleansing - proportion of visualized mucosa $(N=446)$

\begin{tabular}{|l|l|}
\hline Poor & $0(0)$ \\
\hline Fair & $4(0.9)$ \\
\hline Good & $75(16.8)$ \\
\hline Excellent & $367(82.3)$ \\
\hline
\end{tabular}

SB cleansing - proportion of debris, bile and bubbles $(N=446)$

\begin{tabular}{|c|c|c|c|c|c|c|}
\hline \multicolumn{2}{|l|}{ Poor } & \multicolumn{5}{|l|}{$0(0)$} \\
\hline \multicolumn{2}{|l|}{ Fair } & \multicolumn{5}{|l|}{$4(0.9)$} \\
\hline \multicolumn{2}{|l|}{ Good } & \multicolumn{5}{|l|}{$86(19.3)$} \\
\hline \multicolumn{2}{|l|}{ Excellent } & \multicolumn{5}{|l|}{$356(79.8)$} \\
\hline \multicolumn{7}{|c|}{ Colon - cleansing level grading scale } \\
\hline Cleansing & $\begin{array}{l}\text { Cecum, } \\
n=449\end{array}$ & $\begin{array}{l}\text { Ascending, } \\
\mathrm{n}=443\end{array}$ & $\begin{array}{l}\text { Transverse, } \\
\mathrm{n}=434\end{array}$ & $\begin{array}{l}\text { Descending, } \\
n=427\end{array}$ & $\begin{array}{l}\text { Rectum, } \\
\mathrm{n}=249\end{array}$ & $\begin{array}{l}\text { Overall, } \\
n=449\end{array}$ \\
\hline Poor & $32(7.1)$ & $26(5.9)$ & $26(6.0)$ & $27(6.3)$ & $19(7.6)$ & $29(6.5)$ \\
\hline Fair & $87(19.4)$ & $68(15.3)$ & $69(15.9)$ & $72(16.9)$ & $56(22.5)$ & $76(16.9)$ \\
\hline Good & $231(51.4)$ & $238(53.7)$ & $236(54.4)$ & $245(57.4)$ & $146(58.6)$ & $257(57.2)$ \\
\hline Excellent & $99(22.0)$ & $111(25.1)$ & $103(23.7)$ & $83(19.4)$ & $28(11.2)$ & $87(19.4)$ \\
\hline \multicolumn{7}{|c|}{ Colon - bubbles interfering effect scale } \\
\hline & $\begin{array}{l}\text { Cecum, } \\
\mathrm{n}=449\end{array}$ & $\begin{array}{l}\text { Ascending, } \\
n=443\end{array}$ & $\begin{array}{l}\text { Transverse, } \\
n=434\end{array}$ & $\begin{array}{l}\text { Descending, } \\
n=427\end{array}$ & $\begin{array}{l}\text { Rectum, } \\
\mathrm{n}=249\end{array}$ & $\begin{array}{l}\text { Overall, } \\
n=449\end{array}$ \\
\hline Insignificant & $436(97.1)$ & $418(94.4)$ & $375(86.4)$ & $365(85.5)$ & $240(96.4)$ & $335(74.6)$ \\
\hline Significant & $13(2.9)$ & $25(5.6)$ & $59(13.6)$ & $62(14.5)$ & $9(3.6)$ & $114(25.4)$ \\
\hline
\end{tabular}

\section{Cleanliness}

Bisacodyl was taken in $99.3 \%$ and complete PEG + asc intake was achieved in $98.4 \%$ of the participants. Intake of OSS was reported in 373 participants $(82.3 \%$ ) and complete intake was achieved in $93.6 \%$ of the participants. Cleansing of the mucosal surface in the whole gastrointestinal tract was adequate in $52.8 \%$ of the participants. When analyzing the cleanliness of the mucosa per segment, the proportion of visualized stomach mucosa was good (>90\%) in 69.6\%. In the small bowel, both the proportion of visualized mucosa as the proportion of bubbles, debris and bile were good or excellent in $99.1 \%$. The colon cleansing score was good or excellent in $76.6 \%$ and the bubbles effect scale was insignificant in $74.6 \%$. Cleansing scores per segment are listed in $>$ Table 2 .

\section{Transit times}

The completion rate of the colon capsule was $51.9 \%$. In $99.6 \%$ of the participants, the capsule reached the cecum, in $98 \%$ the ascending colon, in $96 \%$ the transverse colon, in $94.7 \%$ the descending colon and in $55.4 \%$ the rectum. Thirteen participants $(2.8 \%)$ doubted if the capsule was excreted and an abdominal $X$-ray was performed. In all participants the capsule was excreted and therefore not visualized on X-ray. CCE median transit time of the whole gastrointestinal tract was 583 minutes (IQR 303-659). Esophageal visualization consisted of just a few images, and therefore a median transit time could not be adequately measured. Z-line objectification was achieved in 44.8\%. CCE median transit time was 55 minutes (IQR 40-92) in the stomach, 47 minutes (IQR 29-78) in the small bowel, and 392 (IQR 191-528) minutes in the colon ( $>$ Table 3). 
- Table 3 Completion rate and transit and reading times for colon capsule endoscopy.

\begin{tabular}{|l|l|}
\hline Total number of procedures & 451 \\
\hline Quality indicators & $231(51.9)$ \\
\hline Completion rate, $\mathrm{n}(\%)$ & \\
\hline Transit times & Median time (min), (IQR) \\
\hline $\begin{array}{l}\text { Period of time CCE in whole gastroin- } \\
\text { testinal tract }\end{array}$ & $583(303-659)$ \\
\hline Period of time CCE in stomach & $55(40-92)$ \\
\hline Period of time CCE in small bowel & $47(29-78)$ \\
\hline Period of time CCE in colon & $392(191-528)$ \\
\hline Reading times by the staff & \\
\hline & Median time (min), (IQR) \\
\hline Whole gastrointestinal tract & $70(57-83)$ \\
\hline Stomach & $3(2-5)$ \\
\hline Small bowel & $10(8-15)$ \\
\hline Colon & $55(43-65)$ \\
\hline
\end{tabular}

$\mathrm{N}$, number; CCE, colon capsule endoscopy; IQR, interquartile range.

\section{Reading times by the staff}

Median time to review one complete CCE procedure was 70 minutes (IQR 57-83). When analyzed per gastrointestinal segment, median reading time needed was 3 minutes for the gastric mucosa (IQR 2-5), 10 minutes (IQR 8-15) for the small bowel mucosa, and 55 minutes (IQR 43-65) for the colonic mucosa.

\section{Patient acceptance}

Of 451 participants, 396 (87.8\%) filled in the first questionnaire prior to the procedure regarding their expectations and 395 $(87.6 \%)$ filled in the second questionnaire after completing the procedure regarding their experience with CCE.

Participants graded the overall CCE procedure with an average of 7.8. Of all participants, $91.1 \%$ would consider undergoing CCE again. Only $6.6 \%$ of participants would advise others against CCE. Most participants (89.2\%) experienced bowel preparation as the most burdensome part of the CCE procedure, the other participants considered the day of the CCE procedure $(8 \%)$ or stomach complaints after the procedure $(3 \%)$ to be the most burdensome part of the procedure.

Regarding the overall burden of the bowel preparation, $22.6 \%$ of participants described the bowel preparation as a little burdensome, $19.8 \%$ fairly burdensome, and $6.4 \%$ strongly burdensome, which was roughly similar to their expectations (> Fig.1). Only $15.8 \%$ experienced no burden at all from the bowel preparation. Regarding the overall burden of the day of the CCE procedure itself, $21 \%$ of participants rated the day of the procedure as a little burdensome, $12.2 \%$ fairly burdensome, and $2.8 \%$ strongly burdensome. The experienced burden was higher than expected, because $17.2 \%$ of participants expected the day of the procedure to be a little burdensome, $6.2 \%$ expected it to be fairly burdensome, and $0.3 \%$ said strongly burdensome. Participants did not experience a lot of shame or pain from the bowel preparation and the CCE procedure, which was roughly similar to their expectations prior to the procedure.

For the specific causes of burden, $89.3 \%$ of the participants said swallowing the capsule was not burdensome. More stomach ache than usual was experienced by only $11.2 \%$ of the participants. The majority of participants (58.9\%) experienced hindrance in daily activities the day of the CCE procedure itself, $40.4 \%$ of the participants had hindrance in daily activities in the day prior to the procedure, and $12.4 \%$ experienced hindrance in the day after the procedure. Only a few participants had trouble sleeping: $28.2 \%$ of the participants the night before the procedure and $8.4 \%$ the night after the procedure.

\section{Safety of the procedure}

A procedure-related AE occurred in 19 participants (4.1\%). The reported $A E s$ were: nausea (1.9\%), abdominal pain (0.6\%), general malaise $(0.6 \%)$, headache $(0.6 \%)$, and vomiting $(0.4 \%)$. All AEs were mild and were the result of ingestion of the bowel preparation.

One non-procedure-related serious AE occurred in a participant who already had melena a few days before ingesting the colon capsule. The afternoon after ingesting the colon capsule, the participant had melena again and was admitted to the hospital. Upper endoscopy was performed and a Mallory Weiss lesion was found as the cause of the bleeding.

\section{Discussion}

This study was the first to investigate the use of CCE as panendoscopy in a large population. We conclude that CCE is a safe method with good patient acceptance. Although cleanliness of each gastrointestinal segment, stomach, small bowel, and colon were good or excellent, the overall cleanliness score per patient was low. Only half of the patients had an overall cleanliness score of at least "good." To use CCE as pan-endoscopy for daily practice, improvement in cleanliness of all segments per patient, a higher completion rate, and solutions to shorten the extensive reading time are warranted.

Using CCE to visualize the mucosa of the gastrointestinal tract has many advantages: it is a noninvasive procedure, without subjection to radiation and sedation, the procedure can be done at home, it can avert endoscopy when no lesions are present, and when a lesion is detected therapeutic endoscopy can directly focus on the lesion found [17]. In patients with occult blood loss or unexplained complaints, it is a good method for observing the entire gastrointestinal tract without using multiple invasive methods, such a upper endoscopy, double balloon endoscopy, or colonoscopy. Therefore, it is a promising diagnostic instrument. However, before introducing CCE as panendoscopy, it is necessary to discuss quality measures for CCE as pan-endoscopy. 
Shamefulness, painfulness and burden of bowel preparation and CCE procedure: expectations beforehand and experiences afterwards

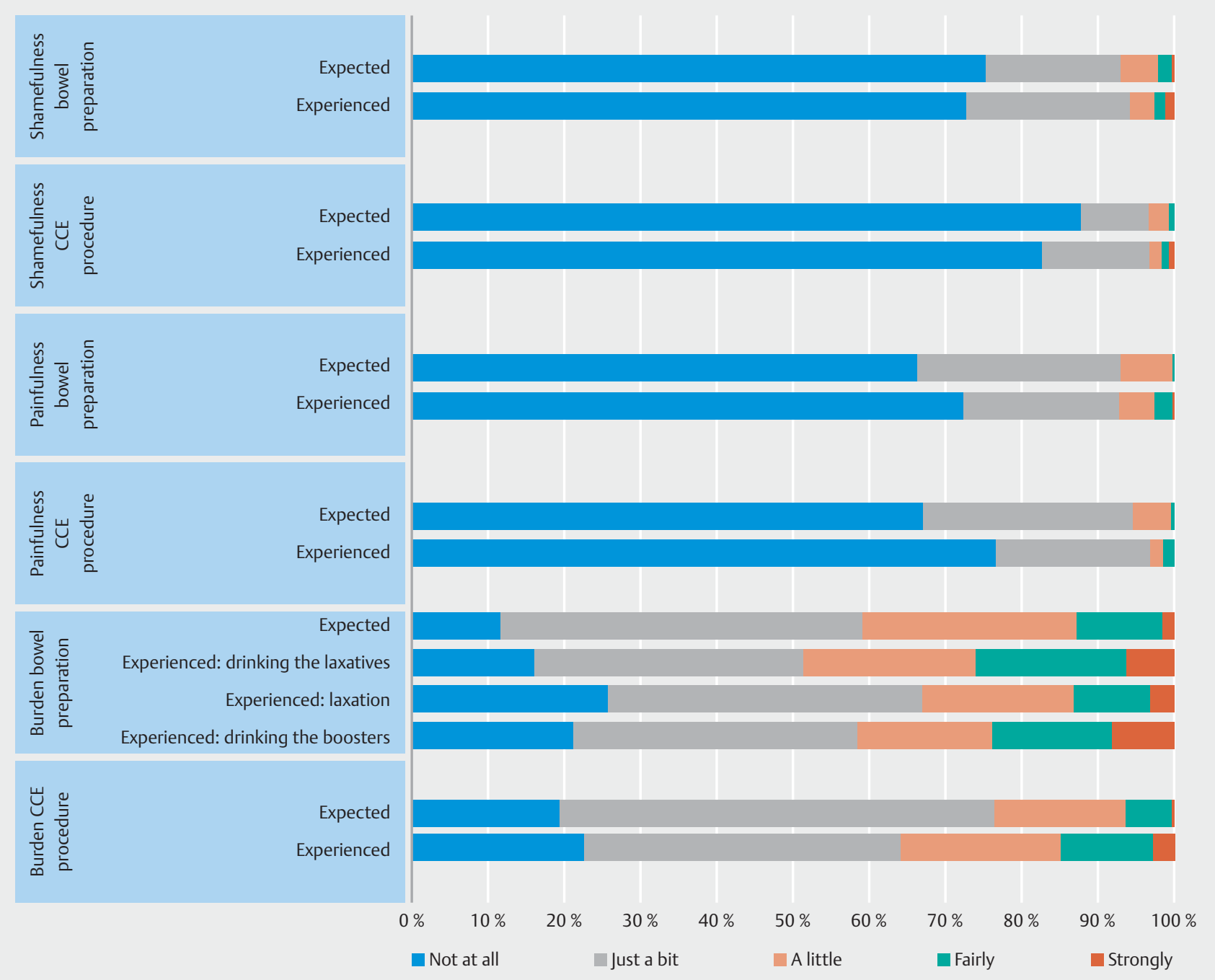

Fig. 1 Shamefulness, painfulness, and burden of bowel preparation and colon capsule endoscopy (CCE) procedure: expectations before and experiences after.

First, the cleanliness of the whole gastrointestinal tract was good in $52.8 \%$ of the participants, which means that all segments of the gastrointestinal tract had a cleansing score of good or excellent. To our knowledge, this is the first cleanliness score developed to score the whole gastrointestinal tract. The whole gastrointestinal tract cleansing score "good" was lower compared to each separate gastrointestinal segment. This is caused by the alternately fair and poor cleansing scores for the stomach and colon and shows that the scores for whole gastrointestinal tract cleansing provide additional insight into the cleanliness of the gastrointestinal tract when CCE is used as pan-endoscopy. The high score for adequate cleanliness of the small bowel (99.1\%) was notable, which could be explained by the large amount of bowel preparation. The European Society of Gastrointestinal Endoscopy recommended in their guideline ingestion of 2 L PEG before small bowel capsule endoscopy [18]. Our bowel preparation consisted of a period of fasting from so- lid food, 2 L PEG + asc and 2 L water split dose. The colon cleansing score was comparable to other studies using the same bowel preparation [19].

Second, the median transit time showed a great variation between the different segments. The Z-line was only observed in $44.8 \%$ of the participants. The Z-line objectification is dependent on both cleanliness and transit time. Participants received extensive bowel preparation to facilitate colonic evaluation, and in most participants, only a few images of the esophagus were retrieved, indicating transit time in the esophagus was too fast. For the stomach, it is well known that the fundus cannot be well observed when using a passive capsule that is propelled only by gastric motility. Therefore, a magnetically guided capsule endoscope has been designed to explore the stomach $[20,21]$. Furthermore, small bowel transit time (47 minutes; IQR 29-78) was faster than expected, based on the literature. A recent study using the Pillcam SB3 (small bowel) capsule 
found a median small bowel transit time of 198.5 minutes [22]. In another study, CCE was used to evaluate the small bowel and showed a small bowel transit time of 61 minutes [23]. Yet the optimal transit time is dependent on the purpose of the examination. For example, when the purpose is to specifically examine the small bowel only, a longer transit time may be warranted, while in case of screening for lesions in the gastrointestinal tract, e.g. to search for causes of anemia, transit time may be accelerated. To use CCE as pan-endoscopy, a fast small bowel transit contributes to a higher completion rate.

In our study, the fast small bowel transit time did not result in an acceptable completion rate, which was only $51.9 \%$ and is lower than in other studies $[19,24]$. The reason for the low completion rate was a long median colonic transit time of 392 minutes (IQR 191-528). In other studies, the median colonic transit times were 6 and 244 minutes [24,25]. Those studies used a $4 \mathrm{~L}$ PEG split dose regimen. It is likely that our bowel preparation or booster regimen was not sufficient to boost the capsule to the anal verge. Sodium phosphate ( $\mathrm{NaP}$ ) was a key component of the bowel preparation for colon capsule for a long time and is used in many trials as a booster [17]. However, $\mathrm{NaP}$ can potentially lead to serious AEs such as acute renal failure and mineral imbalance; therefore, its use is prohibited in some countries $[25,26]$. Even though sulfate solutions have shown to be a good alternative, we showed that in a large population study, the completion rate is low [27]. Alternatives are needed to make CCE an interesting instrument for pan-endoscopy. Besides achieving a higher completion rate, an alternative option for bowel preparation should also take into account that a colonic transit time $<40$ minutes is defined as a technically inadequate study [24].

Third, our study showed that CCE was safe with good patient acceptance. Participants graded colon capsule with a 7.8 and $91.1 \%$ would consider undergoing CCE again in the future. Our results were comparable to a study comparing the experiences of screened individuals undergoing both colonoscopy and CCE [11]. They found that $88.5 \%$ of the screened individuals had a low level of discomfort using CCE versus $35.2 \%$ when undergoing colonoscopy. A recent study assessed patient tolerance and acceptance of three colonic imaging modalities: colonoscopy, CCE, and colonography (CTC) [28]. This study showed that willingness to undergo the same test was high for all three types of colonic imaging: $93.6 \%$ for colonoscopy, $96.1 \%$ for CTC, and $85.7 \%$ for CCE. Fourth, reviewing the images of the entire gastrointestinal tract is time consuming. A solution for using CCE as pan-endoscopy in the most time efficient way is when artificial intelligence (AI) would review the images and highlight abnormalities. Multiple deep learning-based approaches for CCE have been developed, which resulted in higher accuracy and sensitivity. More CCE video databases are needed to develop precise machine learning methods and prospective trials are needed to verify the accuracy of the developed software [29].

This study provided an overview of the applicability of CCE as pan-endoscopy. It was conducted in a large population of healthy participants. There was high compliance with both ingestion of the bowel preparation and boosters and completion of the questionnaires.
This study has several limitations. First, the participants were a relatively elderly population. Aging may slow down colonic transit time, which could have had an impact on the transit times of the colon capsule, resulting in a lower completion rate compared to earlier studies using the same bowel preparation [30]. However, evidence on this matter is scarce. Several studies have not shown a slower colonic transit time in the elderly but have shown delayed gastric emptying in this population [31,32]. Second, the participants were from a select group that were willing to undergo CCE. Therefore, patient acceptance may be higher than when CCE is used for clinical purposes. Third, not all participants filled in the questionnaires, which may have influenced the outcomes. However, of 451 participants, 396 filled in the first questionnaire and 395 filled in the second questionnaire, still resulting in $88 \%$ compliance, which is an acceptable response rate (over $75 \%$ ) for surveys [33].

\section{Conclusions}

To conclude, the current advanced features of the colon capsule make it possible to use CCE as an instrument for panendoscopy. CCE has proven to be safe with good patient acceptance. When technical and procedural issues are resolved, and especially when Al techniques advance, CCE as pan-endoscopy will be a good noninvasive alternative to current (invasive) diagnostic methods to evaluate the gastrointestinal tract.

\section{Acknowledgements}

The authors have received grants from Health Holland, including Medtronic, Camerapil BV, and the Dutch Cancer Society.

\section{Competing interests}

Manon Spander received research support from Medtronic

\section{References}

[1] Pasha SF. Applications of colon capsule endoscopy. Curr Gastroenterol Rep 2018; 20: 22

[2] Spada C, Pasha SF, Gross SA et al. Accuracy of First- and second-generation colon capsules in endoscopic detection of colorectal polyps: a systematic review and meta-analysis. Clin Gastroenterol Hepatol 2016; 14: 1533-1543 e1538

[3] Kjølhede T, Ølholm AM, Kaalby L et al. Diagnostic accuracy of capsule endoscopy compared with colonoscopy for polyp detection: systematic review and meta-analyses. Endoscopy 2021; 53: 713-721

[4] Deding U, Kaalby L, Bøggild H et al. Colon capsule endoscopy vs. ct colonography following incomplete colonoscopy: a systematic review with meta-analysis. Cancers (Basel) 2020; 12: 3367

[5] Spada C, Hassan C, Bellini D et al. Imaging alternatives to colonoscopy: CT colonography and colon capsule. European Society of Gastrointestinal Endoscopy (ESGE) and European Society of Gastrointestinal and Abdominal Radiology (ESGAR) Guideline - Update 2020. Endoscopy 2020; 52: 1127-1141

[6] Cortegoso Valdivia P, Elosua A, Houdeville C et al. Clinical feasibility of panintestinal (or panenteric) capsule endoscopy: a systematic review. Europ J Gastroenterol Hepatol 2021; 33: 949-955 
[7] Spada C, Hassan C, Sturniolo GC et al. Literature review and recommendations for clinical application of colon capsule endoscopy. Dig Liver Dis 2011; 43: 251-258

[8] Singhal S, Nigar S, Paleti $V$ et al. Bowel preparation regimens for colon capsule endoscopy: a review. Therap Adv Gastroenterol 2014; 7 : 115122

[9] Hong SN, Kang SH, Jang HJ et al. Recent Advance in colon capsule endoscopy: what's new? Clin Endosc 2018; 51: 334-343

[10] Koulaouzidis A, Dabos K, Philipper M et al. How should we do colon capsule endoscopy reading: a practical guide. Ther Adv Gastrointest Endosc 2021; 14: doi:10.1177/26317745211001983

[11] Thygesen MK, Baatrup G, Petersen C et al. Screening individuals' experiences of colonoscopy and colon capsule endoscopy; a mixed methods study. Acta Oncol 2019; 58: S71-S76

[12] Vuik FER, Nieuwenburg SAV, Moen S et al. Population-based prevalence of gastrointestinal abnormalities at colon capsule endoscopy. Clin Gastroenterol Hepatol 2020: S1542-3565(20)31506-8 doi:10.1016/j.cgh.2020.10.048

[13] Liao Z, Duan XD, Xin L et al. Feasibility and safety of magnetic-controlled capsule endoscopy system in examination of human stomach: a pilot study in healthy volunteers. J Interv Gastroenterol 2012; 2: 155-160

[14] Park SC, Keum B, Hyun JJ et al. A novel cleansing score system for capsule endoscopy. World J Gastroenterol 2010; 16: 875-880

[15] Leighton JA, Rex DK. A grading scale to evaluate colon cleansing for the PillCam COLON capsule: a reliability study. Endoscopy 2011; 43: 123-127

[16] Park J, Cho YK, Kim JH. Current and future use of esophageal capsule endoscopy. Clin Endosc 2018; 51: 317-322

[17] Spada C, Hassan C, Galmiche JP et al. Colon capsule endoscopy: European Society of Gastrointestinal Endoscopy (ESGE) Guideline. Endoscopy 2012; 44: 527-536

[18] Rondonotti E, Spada C, Adler S et al. Small-bowel capsule endoscopy and device-assisted enteroscopy for diagnosis and treatment of small-bowel disorders: European Society of Gastrointestinal Endoscopy (ESGE) Technical Review. Endoscopy 2018; 50: 423-446

[19] Rondonotti E, Borghi C, Mandelli G et al. Accuracy of capsule colonoscopy and computed tomographic colonography in individuals with positive results from the fecal occult blood test. Clin Gastroenterol Hepatol 2014; 12: 1303-1310

[20] Rey JF, Ogata $\mathrm{H}$, Hosoe $\mathrm{N}$ et al. Blinded nonrandomized comparative study of gastric examination with a magnetically guided capsule endoscope and standard videoendoscope. Gastrointest Endosc 2012; 75: $373-381$
[21] Hosoe N, Naganuma M, Ogata H. Current status of capsule endoscopy through a whole digestive tract. Dig Endosc 2015; 27: 205-215

[22] O'Grady J, Murphy CL, Barry L et al. Defining gastrointestinal transit time using video capsule endoscopy: a study of healthy subjects. Endosc Int Open 2020; 8: E396-E400

[23] Sato J, Nakamura M, Watanabe O et al. Prospective study of factors important to achieve observation of the entire colon on colon capsule endoscopy. Therap Adv Gastroenterol 2017; 10: 20-31

[24] Rex DK, Adler SN, Aisenberg J et al. Accuracy of capsule colonoscopy in detecting colorectal polyps in a screening population. Gastroenterology 2015; 148: 948-957 e942

[25] Pecere S, Senore C, Hassan C et al. Accuracy of colon capsule endoscopy for advanced neoplasia. Gastrointest Endosc 2020; 91: 406-414 e401

[26] Markowitz GS, Nasr SH, Klein P et al. Renal failure due to acute nephrocalcinosis following oral sodium phosphate bowel cleansing. Hum Pathol 2004; 35: 675-684

[27] Kroijer R, Dyrvig AK, Kobaek-Larsen M et al. Booster medication to achieve capsule excretion in colon capsule endoscopy: a randomized controlled trial of three regimens. Endosc Int Open 2018; 6: E1363E1368

[28] Ojidu H, Palmer H, Lewandowski J et al. Patient tolerance and acceptance of different colonic imaging modalities: an observational cohort study. Eur J Gastroenterol Hepatol 2018; 30: 520-525

[29] Hwang Y, Park J, Lim YJ et al. Application of artificial intelligence in capsule endoscopy: where are we now? Clin Endosc 2018; 51: 547551

[30] Madsen JL, Graff J. Effects of ageing on gastrointestinal motor function. Age Ageing 2004; 33: 154-159

[31] Brogna A, Ferrara R, Bucceri AM et al. Influence of aging on gastrointestinal transit time. An ultrasonographic and radiologic study. Invest Radiol 1999; 34: 357-359

[32] O'Mahony D, O'Leary P, Quigley EM. Aging and intestinal motility: a review of factors that affect intestinal motility in the aged. Drugs Aging 2002; 19: 515-527

[33] Draugalis JR, Coons SJ, Plaza CM. Best practices for survey research reports: a synopsis for authors and reviewers. Am J Pharm Educ 2008; 72: 11 